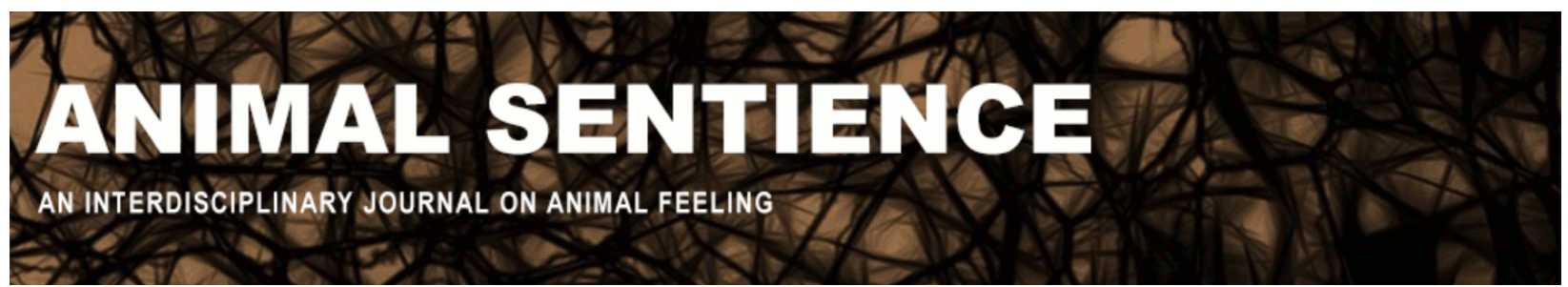

Benvenuti, Anne (2016) Evolutionary continuity of personhood. Animal Sentience 10(13)

DOI: $10.51291 / 2377-7478.1162$

Date of submission: 2016-09-05

Date of acceptance: 2016-09-20

(c)

This article has appeared in the journal Animal

Sentience, a peer-reviewed journal on animal

cognition and feeling. It has been made open access,

free for all, by WellBeing International and deposited

in the WBI Studies Repository. For more information,

please contact

wbisr-info@wellbeingintl.org.

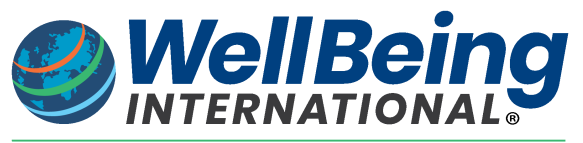

SOLUTIONS FOR PEOPLE, ANIMALS AND ENVIRONMENT 


\title{
Evolutionary continuity of personhood
}

\author{
Commentary on Rowlands on Animal Personhood
}

\author{
Anne Benvenuti \\ Psychology and Philosophy, Cerro Coso College, California
}

\begin{abstract}
Rowlands applies the two organizing ideas of the Lockean concept of personhood mental life and unity - to animals as potential persons. Especially valuable in this context is his descriptive phenomenology of pre-reflective self-awareness as a fundamental form of mental life that necessarily entails unity. Rowland describes certain fundamentals of mental experience that exist across species boundaries, challenging assumptions of early modern philosophers regarding the definition of human personhood and affirming the principle of evolutionary continuity. This opens the door to a broader and deeper set of questions, related to whether we should continue to attempt to apply to other animals - or to ourselves - philosophical models that are ancient and revered but contradicted in significant measure by contemporary scientific findings, especially in evolutionary biology.
\end{abstract}

Keywords: personhood, evolutionary continuity, ontology, animal consciousness, abstract reasoning.

\begin{abstract}
Anne Benvenuti is Professor Emerita, Psychology and Philosophy, Cerro Coso College, California; and Honors Research Fellow, University of Winchester, UK. The author of Spirit Unleashed: Reimagining Human-Animal Relations, her research interests include developing models for scientific investigation of qualia.

http://newarchaic.net
\end{abstract}

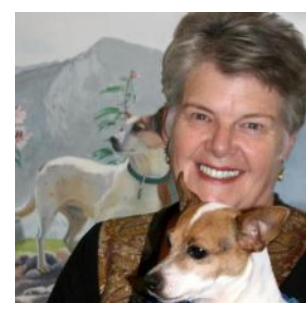

1. Philosophical Models of Personhood. Rowlands (2016) begins his target article by noting that concepts of personhood are variously defined as legal, moral, and metaphysical. He addresses the metaphysical specifically as defined by Locke. Pragmatically speaking, the legal case for animal personhood is advancing in the absence of metaphysical foundation - case by case, as the sciences shape our understanding of other animals and as real life situations make moral demands upon us for remediation (Benvenuti, 2016).

Rowlands produces a convincing metaphysics of personhood satisfying the requirements of the Western philosophical tradition, particularly as advanced by Locke. We must remain aware of the distinction between satisfying the requirements of Western metaphysics as a human cultural artifact and making a true declaration about reality. The Western philosophical tradition has placed high value on the human capacity for rational abstraction. I (Benvenuti, $2014,2016)$ have repeatedly argued that this evaluation of our capacity for rational abstraction - especially as contrasted with affective awareness - lacks merit. Human cognition has 
repeatedly been demonstrated to be largely unconscious, fundamentally affective, and fragmentary, and not the accurate rational perception of early modern philosophers' dreams.

Rowlands notes that many people adopt Locke's concept of personhood, knowingly or unknowingly: The Lockean concept is a big assumption, especially given its roots in Aristotle's (problematic) ontology of beings. The Aristotelian ontology that pervades Western metaphysics deserves reexamination, particularly its notion of human distinctness from and superiority to other animals because of our capacity for abstract thought. Aristotle asserted that all animals share fundamental affective awareness motivated towards experiences that enhance the self and away from experiences that would diminish the self. That, combined with the capacity to move towards and away from experiences, is his definition of animal life. This is quite similar to the pre-reflective awareness described by Rowlands. Aristotle further observed that other animals are incapable of the kind of thinking that allows the mind to move beyond the limits of time and space within which the body is confined. The problem-solving capacity of animals, now well documented, suggests that Aristotle was mistaken. What Rowlands laudably accomplishes with his analysis of Lockean personhood is the detachment of self-awareness and unity from Aristotle's notion of abstract thought and its modern derivative, "higher order" cognition, by developing the category of pre-reflective self-awareness.

2. Evolutionary Continuity and Pre-Reflective Self-Awareness. Rowlands does much more than satisfy the requirements of Lockean personhood for mental experience and unity. His detailed analysis of awareness as self-awareness is reminiscent of Abram's (2011) narrative in Becoming Animal. As animals, we move through a world, knowing it in relation to our particular sensual bodies, motivated to encounter certain things and to avoid others. In other words, our animal bodies determine the shape of the world we encounter: we cannot encounter objects in the world without encountering the self in the same experience. Pre-reflective self-awareness as described and analyzed by Rowlands (after Sartre, 1943) may well be the definition of animal life, including human-animal life.

The principle of evolutionary continuity is based on the evidence that all life descends from a common ancestor, with modifications that enhance adaptation to environmental niches. It follows that all life shares some features, that all animals share a subset of the features of all life, and so forth. Studies of the mammalian brain show primary affective motivational states that cross species boundaries, including an awareness of objects in the world and an embodied readiness to act that is so close to the self/other awareness boundary that these affective experiences might be thought of as the very awakening of consciousness (Panksepp \& Biven, 2012). These primary affects are remarkably similar to Rowlands's description of pre-reflective awareness, particularly to affordances as "perception for action," in which self-awareness is the subjective sense of being oneself and not the more reflective capacity to view oneself as an object of one's own concern. The first type of self-awareness falls into Shoemaker's (1968) category of "immune to error through misidentification," as analyzed by Rowlands: it is possible to doubt that I am correctly seeing my shadow or my image in a reflective surface, but it is not possible to doubt irreducible feeling states. Rowlands makes the strong case that there is a severe logical problem in the idea that we validate self-awareness by moving to greater levels of abstraction, making a distant object of the self. Rather, self-awareness can only be the self of direct experience, the kind of self that we share with other animals. 
On the basis of the principle of evolutionary continuity, we would expect that large categories of experience, such as fundamental motivations, developmental trajectories, communication, and mental life (including fundamental self-awareness) would be shared across species. It is more reasonable to reject ontologies founded in imaginary hierarchical constructions and to conclude that all animals think, feel, intend, and communicate than to assume that they do not. In a similar way, it is more reasonable to expect that animals would share some features of personhood than to doubt a priori that they could do so.

Animal personhood does not mean human personhood in other species. It means that there are probably many forms of expression of person-like features among animal species. These variations are not indicators of lesser personhood but of variance in how personhood is experienced and expressed. Defining animal life in comparison to features of human life makes us devalue animal traits unlike our own, but it prevents us from perceiving the ways a general trait, such as mind or feeling, might exist in other animals.

We can ask how each kind of animal experiences its own self. Rowlands has described the phenomenology of pre-reflective awareness determined by an animal's particular body and sensory apparatus and by its particular needs and desires for in its world of objects. Not all species are highly visual, as is required for Gallup's (1970) mirror self-recognition test: We would not expect cephalopods, who know the world by taste, to recognize a dot placed on their forehead. We would not expect this from dogs. Bekoff (2001) developed a scent-based pilot study using urine to test dog self-awareness. Rowlands's pre-reflective awareness might yield fundamental and shared self-awareness in any kind of body that encounters the world through senses related to motivational states.

3. Human Unconsciousness: The (Human) Psychological Factor. Whereas humans share prereflective self-awareness with other animals, we have an unusual capacity to override basic awareness, especially via our commitment to abstract ideas that color our perceptions and disguise our motivations. Our capacity for abstract thought allows us to distance ourselves from fundamental motives, all the more so when affect is derided as subhuman. When Descartes (1637) said that animals do not feel pain when they cry out, but that they are, in that cry, acting like a mechanical alarm indicating malfunction, he was using the kind of abstract reasoning, "purified" of affective passions, that has since been held up as the pinnacle of cognitive capacity. Yet Descartes's proposition is one that most people today find both wrong and morally offensive. Upon hearing it, they make a "disgust face" - that shared feature of animal life that expresses moral repugnance (Bekoff \& Pierce, 2009, Churchland, 2011). Descartes's affective motivations led him to use abstract thought in a morally convenient and empirically incorrect manner that defies what most of us would call common sense. I do not wish to promote some vague idea of "common sense" over empirical evidence; but there is a rich literature on the "common sense" of body-to-body affective communication by which we know the state of the other implicitly to varying degrees of accuracy, and by which we know that when an animal howls in pain, it feels pain. There is a hint of the deep tragedy of human unconsciousness in the image of Descartes going around with his own companion dog and still insisting that animals are machines.

We Homo sapiens use our capacity for abstract thought to override our pre-reflective self-awareness. This results in beliefs that contradict our pre-reflective awareness and are 
demonstrably contrary to fact. The principle of evolutionary continuity is supported by an abundance of empirical evidence suggesting that personhood is a broadly distributed trait. Rowlands has shown how such evolutionary continuity could still satisfy Locke's philosophical criteria, concluding that "hostility to the idea of animals being persons derives from the Lockean conception of the person, and the idea that self-awareness is necessary for personhood."

It is worth noting the persistence of certain philosophical notions even when contradicted by the evidence. I have described three: the Aristotelian notion that humans are distinct from and superior to other animals because of our capacity for abstract thought; the Cartesian notion that affective "passions" interfere with thought, rather than informing it; and the Lockean notion that only humans have the rational self-awareness required for personhood. Philosophical hostility to the idea of animal personhood may in fact derive from human psychological motives to consider ourselves distinct from and superior to other animals - to be authorized to use other animals de facto, and to avoid painful feelings of empathy for their suffering. We may find not only greater truthfulness but also a richer capacity to conceptualize ways of being persons when we extend our ideas of personhood to our non-human relatives.

\section{References}

Abram, D. (2011). Becoming Animal: An Earthly Cosmology. New York, NY: Vintage Press. Aristotle. (c. 350 BCE). On the Soul (J.A. Smith, Trans.). classics.mit.edu/Aristotle/soul.2.ii.html

Bekoff, M. (2001). Observations of scent-marking and discriminating self from others by a domestic dog (Canis familiaris). Behavioural Processes 55, 75-79.

Bekoff, M., \& Pierce, J. (2009). Wild Justice: The Moral Lives of Animals. University of Chicago Press.

Benvenuti, A. (2014). Spirit Unleashed: Reimagining Human-Animal Relations. Eugene, OR: Wipf and Stock/Cascade.

Benvenuti, A. (2016). Evolutionary continuity and personhood: Legal and therapeutic implications of animal consciousness and human unconsciousness. International Journal of Law and Psychiatry. dx.doi.org/10.1016/j.ijlp.2016.06.001

Churchland, P. (2011). Braintrust: What Neuroscience Tells Us about Morality. Princeton.

Descartes, R. (1637). Discourse on Method (John Veitch, Trans., 1901). www.earlymoderntexts.com/pdf/descdisc.pdf

Gallup, G., Jr. (1970). Chimpanzees: Self-recognition. Science 167(3914), 86-87.

Panksepp, J., \& Biven, L. (2012). The Archaeology of Mind: Neuroevolutionary Origins of Human Emotion. New York: W.W. Norton \& Co.

Rowlands, M. (2016). Are animals persons? Animal Sentience 2016.101.

Sartre, J-P. (1943). Being and Nothingness (H. Barnes, Trans.). Oxford: Blackwell.

Shoemaker, S. (1968). Self-reference and self-awareness. The Journal of Philosophy 65(19), 555567. 